\title{
PATROCÍNIO E MECENATO: FERRAMENTAS DE ENORME POTENCIAL PARA AS EMPRESAS
}

\author{
Ana Carla Fonseca Reis \\ E-mail cainhasp@usp.br \\ Graduada em Administração pela EAESP/FGV e \\ Mestranda em Administração pela FEA/USP. \\ Rubens da Costa Santos \\ E-mail rcsantos@usp.br \\ Professor do Departamento de Mercadologia \\ da EAESP/FGV e da FEA/USP.
}

RESUMO: O Marketing apoiado em atividade de patrocinio e mecenato surge como uma nova tendência da midia. Este artigo busca compreender as especificidades e similitudes dessas novas "ferramentas", além de discutir os maiores desafios a elas associados.

ABSTRACT: Sponsorship, corporate donations, philanthropy, cultural marketing and social responsability are becoming more and more understood and explored by many dynamic companies. This paper presents these concepts, their main characteristics and discusses the major challenges associated with these new tools.

PALAVRAS-CHAVE: patrocinio, mecenato, filantropia, marketing cultural, responsabilidade social. KEY WORDS: sponsorship, corporate donations, philanthropy, cultural marketing, social responsibility. 
1. MEENAGHAN, Tony. Ambush marketing: immoral or imaginative practice? Journal of Advertising Research, New York, v. 34 , n. 5, p. $77-88$, Sept./Oct. 1994.

2. FINN, David. Partnership with the arts. Small Business Report, v. 14, ก. 3, p. 17-9, Mar. 1989.

3. PIQUET, Sylvère. Sponsoring et mécénat: la communication oas levenemement. Paris: Vuibert, $1985,354 p$

4. FEULNER, Edwin J. Giving by objective. Chief Executive, n. 75, p. 16-7, Apr. 1992

5. ALMEIDA, Cândido José Mendes de. Fundamentos do marketing cultural. In: ALMEIDA, Cândido José M.de, DA-RIN, Silvio (org.). Marketing cultural ao vivo Fio de Janeiro: Francisco Alves, 1992, p. 9-21.

6. Idem, ibidem, p. 12

7. SARKOVAS, Yacoff. Negociacảo do projeto cultural. In: ÁLMEIDA, Cândido José M. de., DA-RIN, Silvio. Op. ciłs., p. 14453.

8. INTERNATIONAL ADVERTISING ASSOCIATION (Global Media Commlssion). Sponsorship: its role and effects. New York, Sept. 1988, p. 1.

9. PIQUET, Sylvère. Version antique et version moderne du mécénat. Revue Française de Gestion, Paris, p. 5-17, Mars/ Avril/Mai 1991
A análise da literatura relacionada com as atividades de patrocínio e mecenato revela a proliferação de termos e conceitos, multiplicando formas que, por vezes, designam o mesmo conteúdo. A título ilustrativo, podemos citar Meenaghan ${ }^{1}$, privilegiando o uso dos termos patrocínio e patrocínio comercial. Finn ${ }^{2}$ prefere se referir à parceria. Piquet ${ }^{3}$ desenvolve os conceitos de mecenato e patrocínio, e Feulner ${ }^{4}$, os de doações e filantropia corporativa.

Buscando esclarecer as similitudes e diferenças entre esses termos, nossa linha de estudo será baseada na adoção dos conceitos patrocínio e mecenato. A partir de seus desenvolvimentos, seguiremos analisando seus empregos como ferramentas do composto de marketing das empresas, ressaltando o eventual uso de outros termos, designando, por vezes, as mesmas atividades.

\section{AS ORIGENS DO MECENATO}

Mendes de Almeida ${ }^{5}$ cita três períodos históricos no desenvolvimento do mecenato.

O primeiro deles, que forjou a expressão mecenato, tem origem na figura de Gaius Maecenas, ministro do imperador Caio Augusto, no período de 30 a.C. a 10 d.C. Maecenas foi um grande articulador das ligações entre o Estado romano e o mundo das artes, procurando transferir, para o primeiro, a aceitação e o prestígio dos artistas junto à população. $O$ segundo período do mecenato pode ser considerado o Renascimento, movimento de revalorizaçāo das artes, ocorrido especialmente na Itália, do século XV ao XVII. Nobreza e clero incentivavam produções artísticas, como forma de expressão de seu poder.

Por fim, o terceiro período situa-se no início do século XX, nos Estados Unidos. O capital emigrado da Inglaterra, investido em novas indústrias, fez a fortuna de famílias emergentes (Whitney, Rockefeller e Ford), desejosas de aceitação e reconhecimento da comunidade. Para Mendes de Almeida, "esse mecenato (contemporâneo) se define, portanto, pelo personalismo na decisāo, por nāo ter características eminentemente mercadológicas e pelo necessário e permanente usufruto das benesses fiscais" ${ }^{\prime \prime}$.

\section{A associação sistemática entre a atividade cultural e a comunicação empresarial é uma experiência recente, não apenasino Brasil.}

Entretanto, Sarkovas ${ }^{7}$ ressalta que, embora o mecenato exista há milênios, "a associação sistemática entre a atividade cultural e a comunicação empresarial é uma experiência recente, não apenas no Brasil"

Tal postura é corroborada pela International Advertising Association, organização que, sediada nos Estados Unidos, congrega representantes de 74 países. Para esta associação, o apoio contemporâneo às artes, aos esportes e às atividades afins adquire expressão diferenciada daquele praticado na Antigüidade, ao contar com uma motivação essencialmente comercial. Nesta concepção, a origem do patrocínio remontaria a meados do século XIX, quando a empresa inglesa Spiers \& Pond, em um campeonato na Austrália, patrocinou o time inglês de cricket $^{8}$.

Em contraponto, no contexto francês, Piquet ${ }^{9}$ concorda que o mecenato moderno, praticado por empresas industriais, possui traços fundamentalmente distintos dos do mecenato antigo, o que pode ser explicado por estas três características:

- campo de aplicação: o mecenato moderno diferencia-se do antigo por nāo mais se limitar à área das artes, sendo hoje aberto aos campos tecnológico, social etc.;

- qualidade e multiplicidade dos participantes: o mecenato moderno aparece como uma forma independente dos sistemas políticos, ao contrário de sua forma anterior, basicamente utilizada por círculos oficiais de poder, a saber, governantes e religiosos;

- modo de intervenção: o mecena to clássico apresenta um caráter fortemente in- 
dividualista, enquanto o moderno possui um caráter coletivo, devendo integrar os objetivos da estratégia global de comunicações da empresa.

Nota-se, neste ponto, a característica distintiva entre mecenato moderno e filantropia. O mecenato deixa de ser uma atividade desinteressada, assume um compromisso com a estratégia empresarial $e_{\text {, }}$ na visão dos presentes autores, torna-se mais visível e público diante da comunidade. Para Piquet ${ }^{10}$, o mecenato constitui uma ferramenta do composto de comunicação institucional da empresa, não se revelando um gasto mas um investimento com justificativa econômica, e não mais constituindo um ato de "generosidade pura"

De fato, no contexto brasileiro, a própria legislação de incentivos fiscais à cultura corrobora a diferenciação entre as atividades, com base no modo de exploração do evento. A Lei Rouanet ${ }^{11}$ explicita assim as atividades:

- "mecenato: a proteção e o estímulo das atividades culturais e artísticas por parte dos incentivadores;

- doação: a transferência gratuita, em caráter definitivo, à pessoa física ou à pessoa juridica de natureza cultural sem fins lucrativos, de numerário, bens ou serviços para a realização de projetos culturais, vedado o uso de publicidade paga para divulgaçāo desse ato;

- patrocínio (envolvendo dois aspectos): a transferência gratuita, em caráter definitivo, para pessoa física ou jurídica de natureza cultural com ou sem fins lucrativos, de numerário para a realização de projetos culturais com finalidade promocional e institucional de publicidade e a cobertura de gastos ou utilização de bens móveis ou imóveis, do patrimônio do patrocinador, sem a transferência de domínio, para a realização de projetos culturais por pessoa fisica ou jurídica de natureza cultural, com ou sem fins lucrativos".

Baux $^{12}$, após análise da literatura sobre este assunto, conclui que os autores que se dedicam à questão estabelecem diversos critérios de diferenciação entre as atividades (ver quadro 1). Entretanto, o único consenso está relacionado ao modo de exploração da atividade. Um modo sistemático, no caso do patrocínio, e o mais discreto possível, no caso do mecenato.

Partilhando da mesma opinião sobre a dificuldade prática de explicitação das diferenças entre mecenato e patrocínio, a International Advertising Association é enfática: a existência de uma área nebulosa na fronteira entre os dois conceitos é assegurada pelo fato de que, eventualmente, os próprios patrocinadores optam por um misto de motivações filantrópicas e comerciais. Ao propor uma forma de separação das atividades, a associação cita David Way: "O teste ácido é ver se o doador está preparado para apoiar (a atividade) de forma anônima"13.

Buscando desenvolver o arsenal teórico de diferenciação entre os conceitos, na realidade alemã, Zentes e Deimel ${ }^{14}$ consideram que as distinções ocorrem já na natureza das relações de troca, como citado a seguir:

- o patrocínio se caracteriza por uma relação de troca do tipo prestação/contraprestação. O patrocinador fornece recursos (por exemplo, financeiros, serviços, produtos) e o patrocinado fornece contraprestações que favorecem, direta ou indiretamente, os objetivos de marketing do primeiro (como os relativos à imagem de marca). O patrocínio é acordado em função de uma decisão estratégica da empresa, tendo como ponto de partida seu público-alvo;

\begin{tabular}{|c|c|c|}
\hline \multicolumn{3}{|c|}{ Crítérios de diferenciação entre pairncínio e mecenato } \\
\hline Tipo de Atividade & Patrosinlo & Mecenato \\
\hline Campo de intervenção & Esporte & Artes e cultura \\
\hline Finalidade & Comercial & Cultural \\
\hline Objetivos & $\begin{array}{l}\text { Notoriedade e imagem de } \\
\text { marca }\end{array}$ & Valorização da empresa \\
\hline Técnicas utilizadas & $\begin{array}{l}\text { Semelhantes às técnicas da } \\
\text { propaganda }\end{array}$ & $\begin{array}{l}\text { Semelhantes às técnicas das } \\
\text { relaçōes públicas }\end{array}$ \\
\hline Mẹio de explaraçấo & Sistemático & Discreto \\
\hline Controle da atividade & Total ou parcial & Nenhum \\
\hline $\begin{array}{l}\text { Característica do } \\
\text { contrato }\end{array}$ & Obrigaçōes reciprocas & $\begin{array}{l}\text { Relação de mão única, centrada } \\
\text { no financiamento }\end{array}$ \\
\hline
\end{tabular}

10. Ao mesmo tempo, Piquet defende que a diferença entre patrocínio e mecenato está em que o primeiro pressupōe sempre uma relaçāo de troca. Quanto ao segundo, o autor cita: "Se busca um resultado, nāo tem um valor tão obrigatório como para o patrocinador e conseqüentemente o mecenato tem uma dimensão mais espiritual, porque é sempre marcado por um ato de generosidade" (p.16). Dessa forma, a caracteristica distintiva básica entre patrocínio e mecenato seria entāo a "generosidade da açāo".

11. MUYLAERT, Roberto. Marketing cultural \& comunicaçāo dirigida. Sāo Paulo: Globo, 1993, p. 281-2.

12. BAUX, Philippe. Modèles de persuasion et parrainage sportif Revue Francaise du Marketing Paris, n. 131, p. 51-67, 1991.

13. INTERNATIONAL ADVERTISING ASSOCIATION. Op. cit. p.2.

14. ZENTES, Joachim, DEIMEL, Klaus. Mécénat, encouragement à la culture, sponsoring: de nouvelles chances pour le marketing. Revue Française du Marketing, Paris, n. 131, p. 13$29,1991$.

- 
15. Idem, ibidem, p. 14.

16. COGILL, J. H. Sponsorships and corporate contributions. Canadian Business Review, v. 18 n. 3, p. 16-8, Autumn 1991

17. Idem, ibidem, p. 16-7.

18. EPSTEIN, Marc. The fall of corporate charitable contributions. Public Relations Quarterly, v. 38, ก. 2, p. $37-9$, Summer 1993.

19. SCHREIBER, Alfred, LENSON, Barry. Lifestyle \& event marketing. New York: McGrawHill, 1994, 263p.

20. DWEK, Robert. Doing well by giving generously. Marketing, $\mathrm{p}$. 16-8, July $23,1992$.

21. Idem, ibidem.
- o mecenato é uma forma de apoio à cultura, cuja contraprestação não visa em primeiro lugar a atingir os objetivos de marketing. "São preferencialmente dimensões não-materiais que são buscadas, como o reconhecimento do apoio, o prestígio e a demonstração de uma responsabilidade mo$\mathrm{ral}^{\prime \prime 15}$.

Entretanto, cumpre ressaltar que os objetivos de marketing da empresa, inclusive quanto à construção ou ao aprimoramento de sua imagem, podem constituir "dimensões não-materiais". Para esses autores, porém, há no mecenato uma prevalência dos interesses esportivos, culturais ou socioeconômicos.

Cogill ${ }^{16}$, por sua vez, lança luz adicional sobre a questão, com base na realidade canadense. Privilegiando a utilização de doações corporativas para o mecenato, ressalta que a confusão entre os diversos ter-

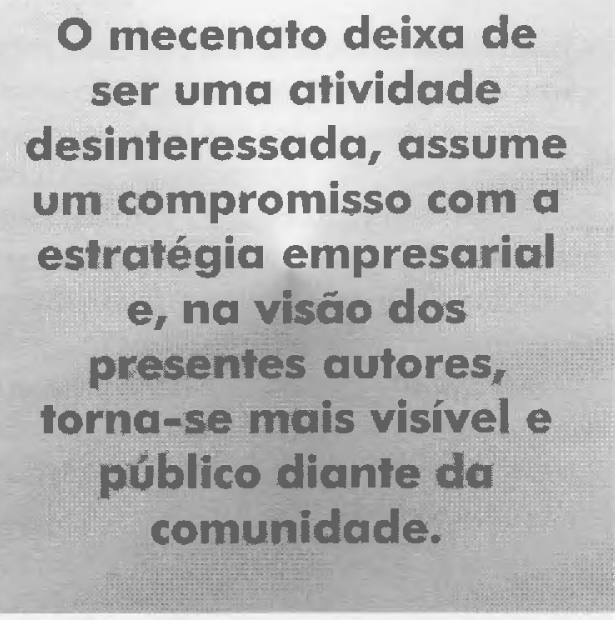

mos pode se dever às semelhanças existentes entre doações e atividades de patrocínio. Para esse autor, ambos os programas permitem à empresa não só comunicar seus valores a um público visado como também enriquecer e fortalecer os laços com as comunidades onde opera. Mas as semelhanças param por aí. "Patrocinio é marketing. Como qualquer estratégia de marketing, espera-se que produza resultados tangiveis: publicidade, maior conhecimento e até resultados comerciais concretos. Já a filan- tropia é uma doação de fundos, tempo ou equipamento que uma empresa faz, enquanto cidadã corporativa. Os resultados são de mais longo prazo e intangiveis, mas igualmente críticos para o sucesso da empresa". Segundo Cogill, ao fazer contribuiçōes, a empresa reconhece sua responsabilidade para com todos os grupos que lhe dão "licença para operar": funcionários, fornecedores, clientes, público em geral. "Embora muito da manutenção dessa licença envolva fazer lucro, nenhuma empresa opera somente em um compartimento isolado, denominado 'econômico' "17.

\section{A questão da responsabilidade social}

A questão da existência de uma responsabilidade social da empresa, em contraposição à corrente que vê como irracional sua atuação fora do campo econômico, tem suscitado enorme gama de posições. Epstein ${ }^{18}$ afirma que "as empresas realmente têm a obrigação de ser socialmente responsáveis mas talvez as contribuiçōes devam ser feitas em áreas onde existam vantagens comparativas". Para esse autor, o envolvimento social só é compensador se considerado como qualquer outra atividade da empresa: com planejamento, execução e avaliação rigorosos, baseados nos objetivos da instituição. A postura da empresa frente à filantropia é alterada e passa a ser vista como uma forma de compartilhamento com os valores e atitudes de seus consumidores, conforme ressaltam Schreiber e Lenson ${ }^{19}$.

Nessa mesma linha, Dwek ${ }^{20}$ ressalta que a proliferação da utilização de atividades filantrópicas como ferramentas de marketing das empresas deu origem à expressão "marketing relacionado a causas". Para ele, a filantropia tradicional é, então, vista sob um novo ângulo, contribuindo com um impacto tangível no resultado das empresas. O grande diferencial é que todos ganham: a empresa atinge seus objetivos estratégicos, as instituições que não objetivam ter lucro obtêm os recursos solicitados e o consumidor sente-se participante de ações que fazem do mundo um lugar melhor.

Dwek ${ }^{21}$ cita a campanha de US\$ 8 milhões desenvolvida pela Texaco, nos Estados Unidos, em 1990, como exemplo de 
pioneirismo no marketing de causas. Em colaboração com o governo norte-americano num programa de redução de acidentes nas estradas, a empresa lançou uma grande campanha na televisão e distribuiu adesivos em sua rede de postos no país. As vendas explodiram, já que, ao buscar os adesivos, as pessoas acabavam abastecendo seus carros. Houve uma redução no número de acidentes nas estradas e os consumidores sentiram-se participantes desse sucesso.

Da mesma forma, Chris Sutherland, diretor da Promotion Marketing Association of America, declara que "as empresas estão analisando como geralmente fazem doaçōes para as caridades e reexaminando a verba doada, para determinar como podem impulsionar seu marketing através delas" 22 .

Reiss ${ }^{23}$, um dos pioneiros da defesa de avaliação das doações corporativas com base nos objetivos de marketing da empresa, coloca-se no papel de um empresário da década de 1970, ao expressar: "Não estarei explorando as artes se eu quiser receber algo promocional em troca do meu dólar. Quando faço uma doação para instituiçōes de ensino posso receber, em troca, um executivo. Quando faço doação ès artes também quero alguma coisa em troca". Para Reiss, portanto, a questão do apoio financeiro pode promover perfeita conciliação entre altruísmo e pragmatismo: "Alguns executivos definem auto-interesse no sentido mais estreito - ajuda diretamente ligada a um propósito empresarial claramente identificável - enquanto outros reconhecem que o crescente papel da corporação moderna pede uma interpretação mais ampla: ajuda que pode ter relação com melhoramentos cívicos e comunitários".

Mesmo Milton Friedman, freqüentemente encarado como contrário ao envolvimento das empresas em atividades tidas como filantrópicas, parece ser favorável à nova forma de consideração da filantropia ou mecenato. De fato, Feulner ${ }^{24}$ lembra que Friedman defende a busca do auto-interesse como a única razão para as doações corporativas, que já cumprem seu papel social ao criar riqueza e gerar empregos. Ainda segundo Feulner, para Friedman, se por meio dessas doações a imagem da empresa for valorizada ou se forem incentivados investimentos, seu uso terá sido válido.
Alguns executivos definem auto-interesse no sentido mais estreito ajuda diretamente ligada a um propósito empresarial claramente identificável

Para Feulner ${ }^{25}$, esta também é a visão de muitos empresários de hoje. Justificando, cita declaração do presidente da Arco dos Estados Unidos, Lodwrick Cook, ao defender que a filantropia corporativa deve ser alvo dos mesmos cuidados de todos os outros investimentos feitos com o dinheiro dos acionistas. O retorno é esperado, "não no sentido de ser incorporado às nossas declarações de lucros e perdas mas no de um resultado mensurável, que será refletido em uma sociedade mais saudável".

Nesse sentido, defendendo retornos visíveis de atividades filantrópicas desenvolvidas por empresas, Cogill ${ }^{26}$ menciona pesquisa divulgada no periódico Research in Corporate Social Performance and Policy. Embora nāo detalhe o estudo, revela que, dentre as 32 empresas pesquisadas, as que gozavam de um desempenho social "satisfatório" também alcançavam um nível de lucratividade na média ou acima dela; já aquelas com desempenho "insatisfatório" estavam abaixo da média de lucratividade. Para esse autor, as "doações são um investimento, embora de um tipo diferente dos outros que a empresa faz usualmente. E, como um investimento, devem ser tratadas com a mesma filosofia e planejamento das outras estratégias da empresa - incluindo o patrocínio de eventos".

\section{O patrocínio}

Buscando esclarecer o arsenal de conceitos utilizados, cabe agora definir mais especificamente o termo patrocínio. Nesse sentido, a proposta de Sandler e Shani ${ }^{27}$ nos parece adequada, porque entende por patrocínio "a provisão de recursos (por exemplo, dinheiro, pessoal e equipamento) por uma organização, diretamente para um evento ou
22. FREEMAN, Laurie, WALLEY, W. Marketing with a cause takes hold. Advertising Age, Chicago, v. 59, ก. 21, p. 34, May 16 , 1988.

23. REISS, Alvin. Responsabilidade cultural da empresa. São Paula: Ibrasa, 1975, 294 p.

24. FEULNER, Edwin J. Op. cit.

25. Idem, ibidem, p. 16-7

26. COGILL, J. H. Op. cit.

27. SANDLER, Dennis, SHANI David. Olympic sponsorship vs. 'ambush' marketing: who gets the gald? Journal of Advertising Research, New York, y. $29, n .4$, p. 9-14, Aug./Sept. 1989. 
28. ETTORRE, Barbara. Heading them off at the pass. Management Review, New York, v. 82 , ก. 3, p. 53-7, Mar. 1993.

29. MEENAGHAN, Tony, Op, cit.

30. TOBIAS, Sarah. Aligning contributions to corporale vision. Canadian Business Review, v. 18, n. 3, p. 24-6, Autumn 1991.

31. SCHREIBER, Alfred, LENSON, Barry. Op. cit.

32. BATTERSBY, Mark. Contribution of ad? Bank Marketing, v. 24, n. 6, p. 24-6, June 1992.

33. ETTORRE, Barbara, Don't just think global marketing. Breathe it. American Mana. gement Association, v. 83, n. 9, p. 39, Sept. 1994

34. SCHREIBER, Alfred, LENSON, Barry. Op. cit.; BATTERSBY, Mark. Op. cit.; PIQUET, Sylvère. Sponsoring el mécénat: la communication. $0 p$. cit. atividade, em troca de uma associação direta com esse evento ou atividade. A organização provedora pode então usar essa associação direta para atingir seus objetivos corporativos, de marketing ou de comunicações".

A relevância da atividade pode ser constatada pela difusão vertiginosa dos eventos de patrocínio, conforme ilustrado por Ettorre $^{28}$, quando elenca a evolução do investimento corporativo na compra de direitos de patrocínio das Olimpíadas.

Em 1996, nas Olimpíadas de Atlanta, empresas investiram cerca de US\$ $500 \mathrm{mi}$ Ihões (projeção), ao passo que em 1992, em Barcelona, o investimento foi de US\$ 354 milhões (doze patrocinadores, entre empresas espanholas e internacionais), em 1988, em Seul, US\$ 100 milhões (nove patrocinadores), e, em 1984, em Los Angeles, US\$ 164 milhões sem nenhum patrocinador estrangeiro.

Para Meenaghan ${ }^{29}$, a evolução apontada é o resultado do desejo dos profissionais de marketing de abrirem novas e compensadoras linhas de acesso aos clientes. Complementarmente, Tobias ${ }^{30}$ atribui esse crescimento às fortes transformações econômicas, políticas e sociais que levaram as empresas a repensarem seus conceitos de patrocínio, - enquanto ferramenta do composto de marketing - e filantropia. Para essa autora, os interesses das empresas e das comunidades em que se inserem tendem a se unificar, consolidando sua parceria por meio da adoção da cultura do patrocínio.

Visando a esclarecer as transformaçōes mencionadas, podemos nos apoiar em algumas importantes tendências presentes em diversos estudos da área:

\section{O uso do patrocínio como ferramenta de marketing possibilita à empresa contornar as difleuldades impostas pelás tendências atucis.}

- a questão da segmentação do mercado é considerada fundamental por Schreiber e Lenson ${ }^{31}$. $\mathrm{O}$ aumento da participação feminina no mercado de trabalho, o maior poder econômico e conscientização alcançados por grupos étnicos, assim como a emergência de uma geração jovem habituada à mídia tradicional mas cética quanto às mensagens transmitidas, levam à segmentação crescente dos públicos-alvo. Seus integrantes querem e devem ser considerados em suas especificidades e com aspirações exigências particulares;

- a escalada dos custos de veiculação de campanhas nas mídias eletrônica e impressa tem forçado as empresas e suas agências de comunicação a buscarem formas alternativas para atingirem seus objetivos, como lembra Battersby ${ }^{32}$. Paralelamente, algumas indústrias (por exemplo, de tabaco e álcool) vêm sendo legalmente banidas das mídias tradicionais;

- a globalização impõe novos desafios para as empresas. Transpor barreiras geográficas e culturais representa uma condição sine qua non para a sobrevivência das instituições. Kotler ${ }^{33}$ declara que "esta é uma época crítica para o marketing. Muitos de nús serũo obsoletos. (...) Você não pode mais contratar um profissional de marketing que nāo saiba fazer análises geodemográficas e de valor percebido pelo consumidor";

- a padronização das imagens das empresas e especialmente dos produtos e serviços prestados, resultado direto da rápida difusāo de aprimoramentos tecnológicos, tem feito com que instituições busquem formas de se diferenciar na mente do consumidor. Daí também a maior eficácia do patrocínio nos objetivos empresariais de longo prazo (por exemplo, na construção da imagem corporativa), obtida com a repetição periódica dessa atividade, tal como citam Schreiber e Lenson; Battersby; Piquet $^{34}$;

- a maior disponibilidade de tempo de lazer leva os indivíduos a buscarem novas formas de auto-realização, por meio de atividades que reúnam seu núcleo fa- 
miliar ou social. Nesse sentido, as atividades esportivas, culturais e eventos de forma geral despertam particular interesse, permitindo participação direta, ao vivo; ou indireta, via transmissões pela mídia. Tratam desse tema Zentes e Deimel; International Advertising Association $^{35}$.

Diversos autores aqui apresentados consideram que o uso do patrocínio como ferramenta de marketing possibilita à empresa contornar as dificuldades impostas pelas tendências atuais, promovendo:

- mudança de atitudes para com a marca ou a empresa ${ }^{36}$;

- adesão do corpo de funcionários e da rede de vendas. Cogill ${ }^{37}$ ressalta que as atividades de patrocínio constituem excelentes oportunidades para cimentar relações entre funcionários e clientes, sejam estes atuais ou potenciais. Esse autor relata declaração de George Cobbe, presidente da Hewlett-Packard do Canadá, revelando que as vendas estagnadas por vários meses foram concluídas na semana seguinte a um concerto organizado pela empresa para altos executivos de empresas clientes;

- reforço ou aprimoramento da imagem corporativa ${ }^{38}$;

- maior conhecimento da marca ou da empresa $^{39}$;

- construção de credibilidade por meio da transferência de atributos relacionados ao evento patrocinado (por exemplo, dinamismo dos esportes, elegância das artes, pioneirismo da ciência) à empresa patrocinadora ${ }^{40}$.

Cogill ${ }^{11}$ estende os limites dos benefícios obtidos das atividades de patrocínio: "as vantagens dos patrocínios são limitadas apenas pela criatividade do próprio patrocinador".

\section{Os campos de ação do patrocínio}

No que se refere à parte operacional da atividade de patrocínio, Zentes e Deimel $^{42}$ definem três campos de ação possíveis:

- esportivo: para esses autores, constitui o campo de patrocínio mais importante para as empresas, podendo se concretizar através do patrocínio de atletas, equi- pes ou provas. Apesar de outras formas de patrocínio estarem apresentando maior crescimento do que essa, em esportes $^{43}$, Schreiber e Lenson ${ }^{44}$ citam que, segundo o International Events Group, $70 \%$ dos patrocínios ainda lhe são dirigidos;

- cultural: para Finnn ${ }^{45}$, uma idéia de apoiar as artes, mesmo partindo de um alto executivo, só obterá o apoio da empresa quando se mostrar relevante para os objetivos globais da instituição. Ademais, Battersby ${ }^{46}$ lembra que, além de atingir os objetivos de marketing da empresa, o patrocínio cultural ainda permite à mesma deduzir parte do investimento de seus impostos. $\mathrm{O}$ aspecto do abatimento fiscal, entretanto, não parece ser funda-

\section{As novas exigências ambientais e as tendências de transformação do mercado parecem exigir que as diversas atividades sejam pensadas cada vez mais em termos globais.}

mental para o engajamento empresarial na atividade. Segundo João Madeira ${ }^{47}$, gerente de comunicação social da Shell, "o apoio à cultura contribui muito para que a imagem da empresa seja positiva. Por isso, no mundo inteiro, a Shell apóia projetos nessa área, com ou sem lei de incentivo fiscal";

- social: dirigido à participação corporativa nas obras de interesse social, constitui o campo de ação do marketing de causas: ambiente, higiene pública, saúde e pesquisa científica. Como exemplo, Schreiber e Lenson ${ }^{48}$ citam o programa Hands Across America, desenvolvido nos Estados Unidos em 1986 pela CocaCola e pelo Citibank, buscando combater a fome no mundo. Segundo os autores, o evento atraiu 4.124.000 pessoas, às quais também foi transmitida a mensa-
35. ZENTES, Joachim, DEIMEL, Klaus. Op. cit.; INTERNATIONAL ADVERTISING ASSOCIATION. Op. cit.

36. EPSTEIN, Marc. Op. cit.; MEENAGHAN, Tony. Op. cit.

\section{COGILL, J. H. Op. cit.}

38. EPSTEIN Marc. Op. cit. MEENAGHAN, Tony. Op. cit:; COGILL, J. H. Op. cit.; FEULNER, Edwin J. Op. cit.

39. MEENAGHAN, Tony. Op. cit.; SCHREIBER, Alfred, LENSON, Barry. Op. cit.; ANNE, Frédéric, PÉRON, Emmanuel J. Mesure de l'efficacité du sponsoring: une analyse des effets intermédiaires sur l'audience directe de l'événement. Revue Française du Marketing, Paris, n. 131, p. 6981,1991

40. MEENAGHAN, Tony. Op. cit;; SCHREIBER, Alfred, LENSDN, Barry. Op. cit.

41. COGILL, J. H. Op. cit., p. 17.

42. ZENTES, Joachim, DEIMEL, Klaus. Op. cit.

43. SNOWDON, Ros. Footing the bill to ring the till. Marketing, p. 22-3, Nov. 24, 1994.

44. SCHREIBER, Alfred, LENSON, Barry. Op. cit.

45. FINN, David. Op. cit.

46. BATTERSBY, Mark. Op. cit.

47. MADEIRA, João. Açôes de marketing cultural I - Sheil. In: ALMEIDA, Cândido José $M$. de. DA-RIN, Sllvio. Op. cit., p. 15463.

48. SCHREIBER, Alfred, LENSON, Barry. Op. cit. 
gem de que as empresas patrocinadoras compartilhavam de seus valores e preocupações.

A relação com o marketing de eventos A proliferação de atividades de patrocínio relacionadas a eventos, nas três áreas descritas, facilita a denominação usual da atividade como marketing de eventos. Cabe a ressalva, porém, de que nem sempre o patrocínio é dirigido especificamente a um evento, já que pode ser concedido a uma pessoa (artista ou atleta), a uma equipe ou a uma instituição (time ou instituição cultural).

\section{Além dos atuais e potenciais clientes da empresa, a sociedade como um todo passa a ter acesso a um novo conjunto rico e diversilficado de afividades.}

Entretanto, devido à predominância de literatura sobre patrocínio de eventos, justificada pelo interesse que estes despertam nos veículos de comunicação e no público em geral, cabe uma consideração especial a esse tipo de marketing.

De maneira formal, Baux ${ }^{49}$ define a atividade como "um sistema composto de comunicação, operacionalizado por uma organização, ao redor da associação de seu nome ou de sua marca a um evento de caráter sociocultural (esportivo, artístico, científico)".

Para Zentes e Deimel ${ }^{50}$, a eficácia do marketing de eventos é ampliada, por contar com formas de repercussão complementares ao evento em si. Na verdade, 49. BAUX, Philippe. Op. cit, p.52.

50. ZENTES, Joachim, DEIMEL, Klaus. Op. cit.

51. PLACHTA, Joan. A survival guide to sponsorship. Marketing. p.31-4, Sept. 27, 1990. do, criador de sinergia, maximizando os benefícios do evento (pelo uso de outras ferramentas do composto de comunicações), ampliando a divulgação "boca a boca", e, por último, prolongador do evento, via exploração da mídia, criação de vídeos etc.

Como se observa, portanto, o patrocínio corporativo de um evento é caracterizado pelo envolvimento da empresa com o mesmo, em contrapartida à divulgação dessa associação e à exploração do fato por meio das ferramentas do composto de masketing. As novas exigências ambientais e as tendências de transformação do mercado parecem exigir que as diversas atividades sejam pensadas cada vez mais em termos globais. Assim, faz-se fundamental que os benefícios auferidos com o patrocínio obtenham sinergia, através da integração da atividade a estes outros programas:

- de promoção: fornecimento de privilégios para clientes atuais/potenciais, funcionários e parceiros comerciais, por meio do fornecimento de entradas, brindes, organização de um "evento prévio" para poucos (pré-estréia, jogo amistoso);

- relações públicas: a difusão do evento nos editoriais de veículos conceituados favorece a credibilidade e a imagem de espontaneidade da ação ${ }^{51}$. As açöes de relações públicas devem atingir todos os segmentos de interesse da empresa, via distribuição de material informativo, "linha $800^{\prime \prime}$ etc.;

- propaganda: divulgação do patrocínio na mídia tradicional, ampliando a faixa de consumidores atuais/potenciais cientes da atividade, assim como de outros segmentos de público de interesse da empresa, constituintes de seu macroambiente.

No que se refere especificamente ao contexto brasileiro, cumpre destacar a iniciativa de Adélia Franceschini e Consultores Associados que, em 1994, desenvolveram pesquisa qualitativa pioneira a respeito do tema, junto a 48 empresas de diferentes áreas de atuação. Buscando perceber aspectos correlatos à visão das instituições 
quanto ao patrocínio artístico-cultural e quanto à forma como este seria utilizado pelas suas diversas áreas e, ainda, os critérios de decisão e dificuldades para o estudo do tema, Franceschini confirmou suspeitas de que as áreas de marketing das empresas estão voltadas para esses conceitos $^{52}$ :

- o produto valoriza os megaeventos. As que tiveram pouca experiência no ramo imaginam que o gasto nunca será superado pelo retorno;

\section{Paralelamente, as atividades de patrocínio encobrem um efeito de sinergia social que não deveria, de forma alguma, ser negligenciado.}

- o mercado considera eventos artísticoculturais para aproximar a empresa de seus públicos-alvo e criar um bom relacionamento com seus clientes. Porém, os custos são elevados, o planejamento é difícil e não visualizam formas de mensurar o retorno;

- os business-to-business consideram os eventos para enriquecer o relacionamento com os clientes, agregando às marcas valores de qualidade, credibilidade, tradição e respeitabilidade.

\section{CONCLUSÕES}

A difusão das atividades de mecenato $e$ patrocínio, mormente as relacionadas com eventos, exige e justifica o desenvolvimento de estudos esclarecedores de pontos básicos das açōes. Dentre eles, podemos destacar as formas de seleçāo dos projetos por parte das empresas; a viabilidade de mensuração dos benefícios do patrocínio; os direitos e deveres dos patrocinadores, patrocinados e demais envolvidos na or- ganização do programa. Na prática, notase ainda a absoluta carência de pesquisas no setor.

Em virtude do exposto, muito resta por ser explorado neste campo embrionário e extremamente promissor do marketing empresarial. A própria velocidade com que vem se desenvolvendo acaba por lhe conferir uma aura desafiadora e intrigante, que não passa despercebida pelos pesquisadores e estudiosos do marketing e da comunicação em geral.

Por um lado, o patrocínio e o mecenato representam preciosos recursos empresariais, que poderão ser extremamente alavancadores de muitas de nossas combalidas atividades culturais. A notável e decrescente participação do Estado em áreas vistas como nāo-prioritárias, a exemplo da cultura, abre espaço para que a iniciativa privada tome a dianteira em um processo de inexorável aproximação com a comunidade na qual se insere. As atividades de patrocínio permitem que essa aproximação se efetive, sem, com isso, relegar a busca do lucro empresarial a segundo plano. Da mesma forma, a compreensão dos objetivos perseguidos com programas de patrocínio e mecenato se prestará a guiar agentes e promotores de eventos. Frequientemente dotados de brilhantes idéias e enorme boa vontade, esses profissionais nem sempre logram sucesso em sua aproximação com as empresas, por não disporem de argumentos compatíveis com a visão da comunidade empresarial.

Paralelamente, as atividades de patrocínio encobrem um efeito de sinergia social que não deveria, de forma alguma, ser negligenciado. De fato, a participação financeira das empresas em atividades de cunho esportivo, social e afins garante, muitas vezes, a realização de programas que, de outra maneira, não poderiam se viabilizar. Com sua efetivação, usufruem dos benefícios da ação não apenas os elementos diretamente envolvidos no processo - as empresas patrocinadoras -, os intermediários e os patrocinados. Na verdade, além dos atuais e potenciais clientes da empresa, a sociedade como um todo passa a ter acesso a um novo conjunto rico e diversificado de atividades.
52. FRANCESCHINI, Adélia et al. Arte e empresa: parceria multiplicadora (Primeira Pesquisa Qualitativa sobre Mercado Brasileiro de Patrocinio Cultural). São Paulo: SESC/SEBRAE, 1994. 